\title{
ANALISA KEGAGALAN PADA PIPA ULIR DI LINGKUNGAN PERMINYAKAN FAILURE ANAL YSIS OF TUBING-DRILL PIPES UNDER OIL ENVIRONMENT
}

\author{
Deden Suripto \\ Balai Besar Teknologi Kekuatan Struktur - BPPT \\ Kawasan PUSPIPTEK Gd.220 Serpong, Tangerang 15314 \\ e-mail:deden suripto@yahoo.co.id
}

Tanggal masuk naskah : 18/07/2014 ; Tanggal revisi: 19/09/2014 ; Tanggal persetujuan cetak : 08/10/2014

\begin{abstract}
Abstrak
Penelitian terhadap kerusakan pada pipa ulir pada lingkungan perminyakan ,telah dilakukan. Kegagalan dari suatu komponen dapat disebabkan oleh berbagai macam faktor, mulai dari kesalahan pemilihan material sampai dengan kesalahan operator dalam service-nya. Tujuan penelitian adalah untuk mencari penyebab kegagalan terjadinya cacat pada material tubing setelah dioperasikan. Untuk mengetahui penyebabnya dilakukan analisa kegagalan dengan menggunakan beberapa metode, yaitu: pemeriksan visual dan dimensi, pengujian tarik dan kekerasan, pemeriksaan makroskopis dan mikroskopis, pengujian komposisi kimia bahan, dan pengujian SEM/EDS. Hasil penelitian membuktikan bahwa adanya unsur korosif dalam material seperti $C L^{-}$dan $S^{-2}$ sehingga sangat potensial untuk terjadinya serangan korosi sumuran maupun korosi celah kikisan pada ujung ulir dan akan berpenetrasi pada lapisan pasivasi $\mathrm{Fe}_{2} \mathrm{O}_{3}$ yang sifatnya mengabsorbsi anion-anion agresif seperti $C L^{-}$dan $S^{-2}$
\end{abstract}

Kata kunci : analisis kegagalan, pipa ulir, korosi.

\begin{abstract}
The a research on the damage of tubing-drill pipes at an oil company, has been carried out. Failure of the component may be caused by many factors including material selection and their mishandling during in service. The objective of this research was to find out the reason of any failure or defects of a material during in, some testing methods were used, namely: visual and dimensions test, strength and hardness tests, macroscopic and microscopic test, the chemical analysis of material test, and SEM/EDS test. The results of proved that there were some corrosive elements such as the $\mathrm{Cl}$ and $S^{-2}$ so that there was a the potential for the occurence of pitting and crevice corrosivation at the end of screws and these will be penetrated into the passivation layers of $\mathrm{Fe}_{2} \mathrm{O}_{3}$ that absorb aggressive anions such as $\mathrm{Cl}^{-}$and $\mathrm{S}^{-2}$.
\end{abstract}

Keywords : failure analysis, drill pipe, corrosion.

\section{PENDAHULUAN}

Kerusakan komponen dan peralatan industri harus ditangani secara tuntas penyebab utamanya agar tidak terjadi kerusakan sejenis dimasa mendatang. Kesalahan pemilihan material, kesalahan fabrikasi, ketidaksesuaian jenis material dengan kondisi kerjanya, merupakan contoh penyebab mengapa banyak komponen atau peralatan industri mengalami gagal fungsi dalam pemakaiannya $a^{[1]}$.

Kasus kegagalan sangat merugikan, karena itu untuk menghindari peristiwa serupa maka 
perlu dipelajari sebab-sebab terjadinya kegagalan. Penyelidikan terhadap sebabsebab terjadinya kegagalan akan bermanfaat terutama untuk menghindari kerugian biaya yang berlebihan. Dengan mengetahui sebab kegagalan maka berbagai tindakan pencegahan awal dapat dilakukan. Kesalahan mungkin saja terjadi sejak tahap perencanaan. Kesalahan tersebut bisa disebabkan oleh; kesalahan perencanaan dimensi, kesalahan material, kesalahan penempatan pada kondisi lingkungan tertentu, kesalahan perhitungan tegangan dan lainlain $^{[2]}$.

Berdasarkan kenyataan di atas, makalah ini akan memaparkan analisis kegagalan sehubungan dengan terjadinya cacat pada daerah ujung pipa ulir di perusahaan perminyakan yang berlokasi di Cirebon. Sehubungan hal tersebut, maka perusahaan tersebut mengirimkan dua buah (No 3 dan No 5) potongan pipa ulir yang rusak (cacat) karena korosi untuk dilakukan analisis. Data teknis dari pipa ulir adalah sebagai berikut; material pipa ulir : baja karbon medium dengan spesifikasi API 5 C5 Gr N-80, No 3 mempunyai diameter $73,5 \mathrm{~mm}$ dengan panjang $430 \mathrm{~mm}$, No 5 mempunyai diameter $73,5 \mathrm{~mm}$ dengan panjang $535 \mathrm{~mm}$.

Analisa kegagalan yang dilakukan bertujuan untuk mencari dan mendapatkan informasi penyebab kegagalan terjadinya cacat korosi pipa ulir pada celah ulir luar dan ulir dalam, memberikan gambaran tentang mekanisme kegagalan yang terjadi pada pipa ulir, mencegah, menanggulangi dan memberikan rekomendasi untuk menghindari kegagalan yang sama dikemudian hari kepada manajemen perusahaan minyak tersebut.

\section{Analisa Kegagalan}

Berdasarkan teori analisa kerusakan / kegagalan (failure analysis) ${ }^{[3-9]}$, adalah kegiatan atau usaha untuk menyelidiki sebab-sebab kegagalan suatu komponen. Semua indikasi dipelajari dan diteliti untuk mendapatkan keputusan apakah komponen layak dperbaiki atau tidak. Modus kegagalan bisa berupa keausan. Kegagalan yang ekstrim adalah bilamana komponen mengalami patah atau pecah.

\section{Modus Kegagalan $^{[4]}$}

Komponen akan gagal bila kondisi
kerja menyebabkan besaran operasi
mencapai atau melampaui batas kritis sifat
material. Pertanyaan tersebut dapat
dinyatakan dalam bentuk rumus umum sebagai berikut:

Besaran akibat kondisi operasi $\geq$ Sifat kritis material. Penggunaannya untuk modus berbagai kegagalan dirangkum pada Tabel 1 . Tabel 1 ini hendaknya diartikan bahwa bila besaran akibat kondisi operasi (ruas kiri) mencapai atau melampaui batas kritis sifat material (ruas kanan), maka komponen akan mengalami kegagalan.

Arti lanjut dari bentuk umum kriteria kegagalan tersebut di atas adalah bahwa kegagalan akan terjadi bila:

1. Parameter kiri membesar dan atau

2. Parameter kanan berubah menjadi kecil

Dari logika ini kita perlu mengembangkan semua kemungkinan yang dapat memperbesar ruas kiri (=memperparah kondisi operasi), serta kemungkinankemungkinan yang menyebabkan mengecilnya ruas kanan (=menurunkan sifat kritis material).

Seringkali kegagalan terjadi setelah beberapa waktu beroperasi normal dan aman. Pertanyaannya tentu saja: "Mengapa komponen itu gagal?" Mungkinkah telah terjadi hal atau kondisi yang memperbesar ruas kiri hingga melampaui ruas kanan (sifat kritis material)? Dari konteks material, mungkinkah terjadi degradasi material selama beroperasi ?

Tabel 1. Kegagalan komponen untuk berbagai modus kegagalan

\begin{tabular}{lll}
\hline $\begin{array}{c}\text { Besaran akibat kondisi } \\
\text { operasi }\end{array}$ & \multicolumn{1}{c}{ Sifat kritis material } & \multicolumn{1}{c}{ Peristiwa yang akan terjadi } \\
\hline Tegangan kerja & Kekuatan luluh & Deformasi plastis \\
$\sigma_{\mathrm{w}}$ & $\sigma \mathrm{y}$ & Patah statis \\
\hline Tegangan kerja & Kekuatan tarik & Patah lelah \\
$\sigma_{\mathrm{w}}$ & $\sigma y$ & \\
\hline Tegangan amplitudo & Batas lelah & (Fatigue limit) of \\
$\sigma_{\mathrm{a}}$ & & \\
\hline
\end{tabular}




\begin{tabular}{|c|c|c|}
\hline $\begin{array}{ll}\text { Tegangan } & \text { dinamik } \\
\text { setempat } & \\
\sigma^{\prime}=\mathrm{K}_{\mathrm{t}} \cdot \sigma_{\mathrm{nom}} & \\
\end{array}$ & $\begin{array}{l}\text { Kekuatan luluh } \\
\text { oy }\end{array}$ & Awal retak lelah \\
\hline $\begin{array}{l}\text { Intensitas tegangan } \\
\mathrm{K}=\beta . \sigma \sqrt{ }(\pi \mathrm{a})\end{array}$ & $\begin{array}{lll}\text { Ketangguhan } & \text { retak } & \text { (Fracture } \\
\text { toughness) } & & \\
\mathrm{K}_{\mathrm{c}} \text { atau } \mathrm{K}_{\mathrm{Ic}} & & \\
\end{array}$ & $\begin{array}{l}\text { Komponen yang retak lelah akan } \\
\text { patah }\end{array}$ \\
\hline $\begin{array}{l}\text { Tegangan kerja } \\
\sigma_{\mathrm{w}}\end{array}$ & $\begin{array}{l}\text { Batas mulur } \\
\text { (Creep limit) }\end{array}$ & $\begin{array}{l}\text { Deformasi plastis akibat creep } \\
\text { (pada suhu tinggi) }\end{array}$ \\
\hline $\begin{array}{l}\text { Tegangan kerja } \\
\sigma_{w}\end{array}$ & $\begin{array}{l}\text { Kekuatan terhadap retak korosi } \\
\text { tegangan } \\
\sigma_{\mathrm{scc}}\end{array}$ & Retak akibat korosi tegangan \\
\hline $\begin{array}{l}\text { Suhu lingkungan terlalu } \\
\text { rendah }\end{array}$ & Suhu transisi material & Patah getas (brittle fracture) \\
\hline $\begin{array}{ll}\text { Lingkungan } & \text { terlalu } \\
\text { korosif } & \end{array}$ & Batas korosivitas & Laju korosi yang tinggi \\
\hline
\end{tabular}

\section{Sifat Material ${ }^{[4]}$}

Sifat material ditentukan oleh berbagai hal yang secara arif diformulasikan oleh kelompok peneliti di Departemen MTM Katholieke Universiteit Leuvin Belgia, yaitu; (1) komposisi kimia material, (2) struktur material, (3) tekstur kristalografis, (4) tegangan sisa, (5) permukaan.

Jelaslah bahwa perbedaan dalam parameter material tersebut di atas akan mengubah sifat material. Dalam melakukan analisis kegagalan kesadaran akan hal ini penting dalam meninjau kemungkinan penyebab perubahan sifat material.

Salah satu parameter yang dominan adalah struktur material, makro ataupun mikro. Struktur material dipengaruhi oleh kompensasi material dan dapat berubah oleh proses pengerjaan hingga tahap akhir, bahkan dapat juga berubah selama beroperasi, tergantung pada kondisi operasinya.Struktur Material ${ }^{[4]}$

pemilihan material selalu dikaitkan dengan persyaratan operasi yang harus dipenuhi oleh sifat-sifat material. Secara filosofis, pada masa kini kegiatan disain material itu adalah melakukan desain terhadap struktur material. Oleh karenanya setiap perubahan pada struktur material pasti ada implikasinya pada sifat material itu. Pada Tabel 2 diperlihatkan rangkuman berbagai proses/peristiwa yang mengubah struktur material, baik yang sengaja, maupun tidak sengaja. Isi Tabel 2 ini dapat ditambah dengan peristiwa (mekanisme) lain yang mengubah sifat. Selain itu cacat material sering pula teramati, seperti: inklusi, retak mikro, porositas, blister, lipatan dan seterusnya. Semua itu pasti akan berpengaruh terhadap sifat material.

Tabel 2. Rangkuman berbagai proses yang mengubah struktur material

\begin{tabular}{cll}
\hline No & \multicolumn{1}{c}{ Peristiwa } & \multicolumn{1}{c}{ Sifat material } \\
\hline 1 & Ukuran butir terlalu besar & Menjadi getas \\
\hline 2 & Dekarburisasi & Kekuatan setempat turun \\
\hline 3 & Difusi & Perubahan sifat di permukaan \\
\hline 4 & Sensitisasi (pada stainless steel) & Mudah terserang korosi batas butir \\
\hline 5 & Dezincfication (pada kuningan) & Terjadi korosi selektif \\
\hline 6 & Presipitasi & $\begin{array}{l}\text { Mengubah kekuatan, keuletan, ketahanan lelahdan } \\
\text { fracture toughness }\end{array}$ \\
\hline 7 & Quench \& temper & Terlalu keras atau terlalu lunak \\
\hline 8 & Segregasi & Perbedaan sifat didalam material \\
\hline 9 & Rekristalisasi & Perubahan kekuatan dan keuletan \\
\hline 10 & $\begin{array}{l}\text { Inokulasi dan nodularisasi grafit (pada } \\
\text { besi cor) }\end{array}$ & Kekuatan dan keuletan besi cor \\
\hline
\end{tabular}





\section{BAHAN DAN METODA}

Skema penelitian untuk mencari penyebab kegagalan yang terjadi pada pipa ulir yang dilakukan dengan menggunakan metode failure analysis ditunjukkan pada Gambar 1.

Metoda yang digunakan untuk menganalisis cacat korosi pada daerah ujung pipa ulir adalah metode analisis kegagalan (failure analysis) yaitu suatu langkah pemeriksaan kegagalan atau kerusakan pada suatu komponen yang mencakup situasi dan kondisi kegagalan atau kerusakan tersebut, sehingga dapat ditentukan penyebab dari kegagalan/kerusakan yang terjadi pada daerah pipa tersebut. Langkah ini disertai dengan pemeriksaan dan pengujianpengujian sebagai berikut; pemeriksaan visual dan dimensi, pengujian komposisi kimia, uji tarik dan kekerasan, pemeriksaan makroskopis dan mikroskopis, pemeriksaan Scanning Electrons Microscope (SEM) dan Energy Dispersed Spectometry (EDS).

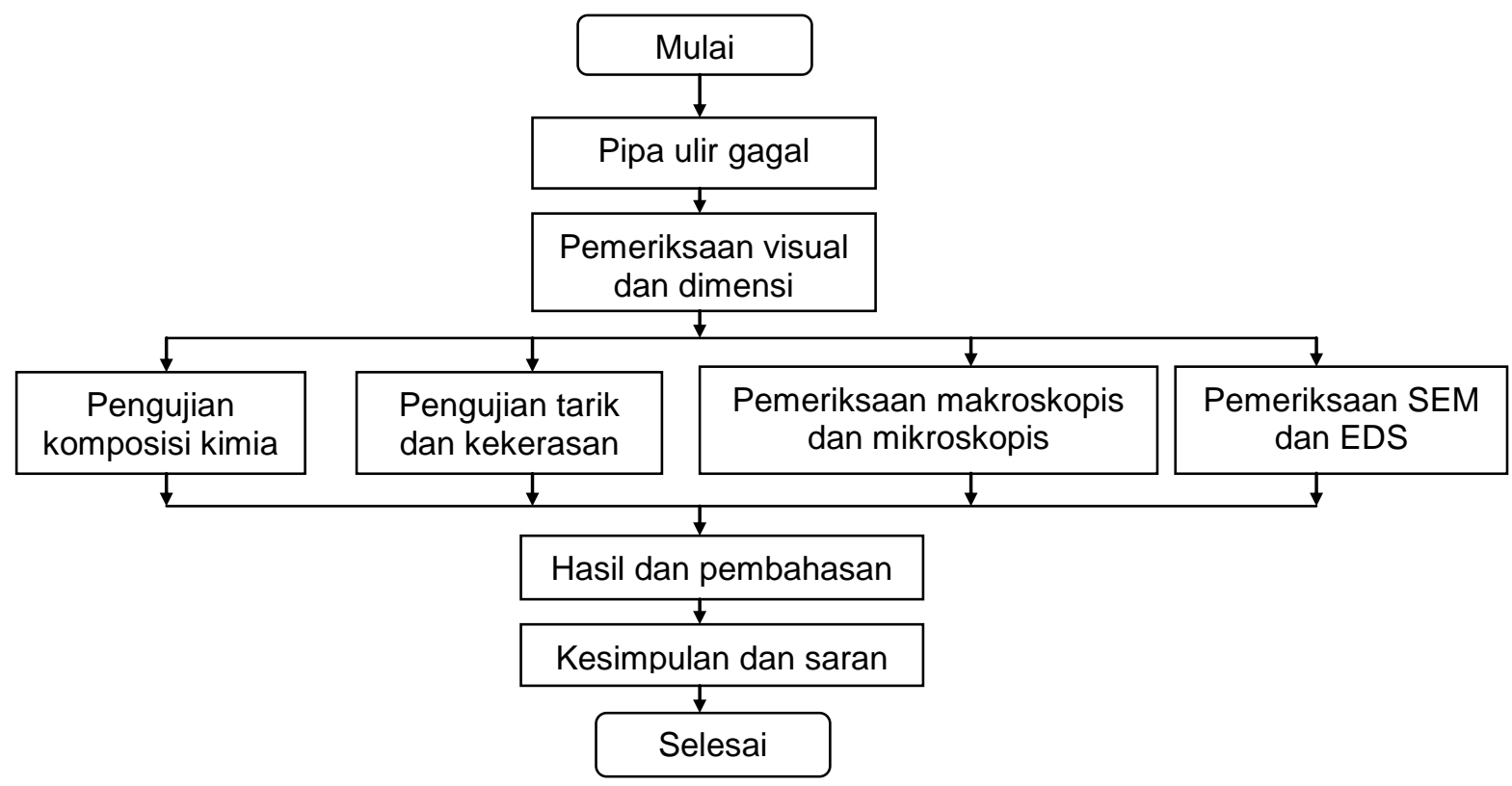

Gambar 1 : Metodologi penelitian

\section{HASIL DAN PEMBAHASAN}

\subsection{Pemeriksaan Visualisasi dan Dimensi}

Pemeriksaan yang pertama kali dilakukan yaitu pemeriksaan visual dan dimensi.
Berdasarkan pengamatan visual pada daerah permukaan luar terlihat adanya korosi merata yang signifikan. Selain itu ada cacat pada daerah ulir tubing yang diprediksi pada daerah ulir tersebut ada celah yang menyebabkan terjadinya korosi celah oleh media korosif (crevice corrossion), sebagai ilustrasi dapat dilihat pada Gambar 2. 


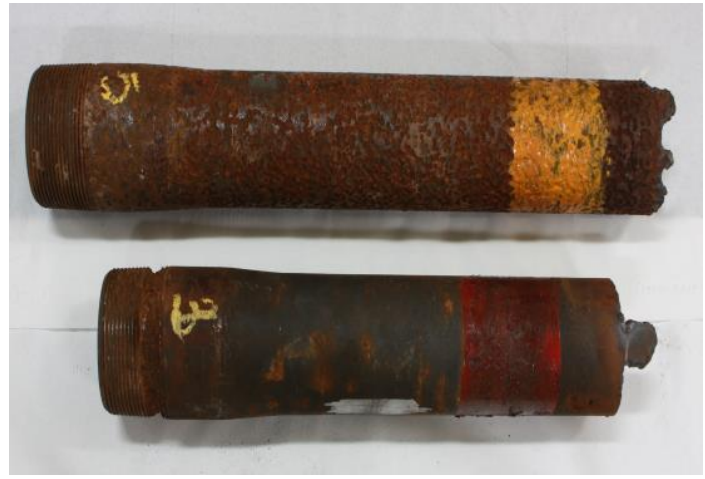

Gambar 2 : Potongan tubing No3: panjang $430 \mathrm{~mm}$, diameter 73,5 mm dan pipa No.5: panjang $535 \mathrm{~mm}$, diameter $73,5 \mathrm{~mm}$

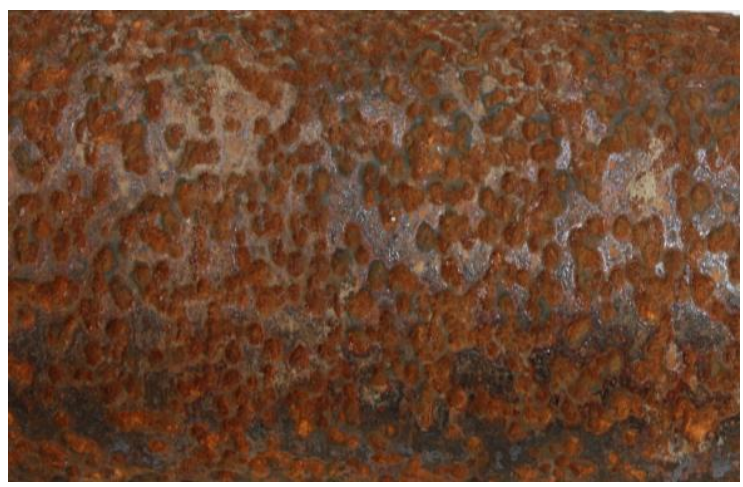

Gambar 3 : Bentuk korosi pada permukaan pipa No.5

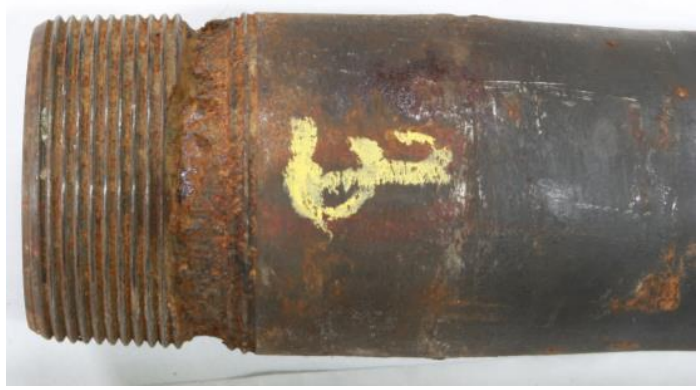

Gambar 4 : Cacat slek pada daerah ujung pipa berulir pipa No.3.

\subsection{Analisis Komposisi Kimia}

Komposisi kimia bahan untuk pipa no.3 dan no.5 (Gambar 2 dan Gambar 4) telah dilakukan penelitian dengan spectrometer (AAS ) yang hasilnya dapat dilihat pada Tabel 3.

Dari hasil uji komposisi kimia dinyatakan bahwa material pipa adalah baja karbon medium dengan paduan rendah. Kehadiran unsur Mn-Cr-Mo dalam material sangat diperlukan untuk menahan gesekan serta tahan terhadap lingkungan korosif. Dari data hasil uji komposisi kimia terbukti bahwa ketiga unsur tsb relatif sangat kecil, dengan demikian material pipa akan rentan terhadap serangan yang bersifat korosif. Sehingga kekuatan material akan menurun akibat gesekan pada beban yang bekerja (beban puntir).

Tabel 3. Hasil uji komposisi kimia pada pipa ulir

\begin{tabular}{cccl}
\hline \multirow{2}{*}{$\begin{array}{c}\text { Unsu } \\
\mathbf{r}\end{array}$} & \multicolumn{2}{c}{$\begin{array}{c}\text { Persentase berat } \\
\text { (\%) }\end{array}$} & \multirow{2}{*}{ API.5CT. } \\
\cline { 2 - 3 } & No3 & No5 & GR.N-80 \\
\hline $\mathrm{C}$ & 0.2804 & 0.32402 & \\
\hline $\mathrm{Si}$ & 0.32775 & 0.35161 & \\
\hline $\mathrm{S}$ & 0.00936 & 0.01138 & $0.03 \mathrm{Max}$ \\
\hline $\mathrm{P}$ & 0.0224 & 0.027 & $0.03 \mathrm{Max}$ \\
\hline $\mathrm{Mn}$ & 1.50522 & 1.48929 & \\
\hline $\mathrm{Ni}$ & 0.00962 & 0.0098 & \\
\hline $\mathrm{Cr}$ & 0.02575 & 0.04321 & \\
\hline $\mathrm{V}$ & 0.11696 & 0.12583 & \\
\hline $\mathrm{Cu}$ & 0.00524 & 0.00546 & \\
\hline $\mathrm{W}$ & 0.00392 & 0.00354 & \\
\hline $\mathrm{Ti}$ & 0.00304 & 0.00305 & \\
\hline $\mathrm{Sn}$ & 0.00304 & 0.00272 & \\
\hline $\mathrm{Al}$ & 0.00379 & 0.00307 & \\
\hline $\mathrm{Zr}$ & 0.00075 & 0.00071 & \\
\hline $\mathrm{Zn}$ & 0.00081 & 0.00054 & \\
\hline $\mathrm{Fe}$ & 97.70902 & 97.60717 & \\
\hline
\end{tabular}

\subsection{Uji Tarik}

Pada Tabel 4 diperlihatkan hasil uji pipa ulir. Menujukkan spesifikasi material termasuk material pipa ulir yang mempunyai ketangguhan cukup kuat, karena diperuntukkan untuk beban tinggi, disamping itu tingkat elongasi mempunyai nilai cukup. Jadi hasil uji tarik masih memenuhi persyaratan sifat mekanik untuk pipa ulir. 
Tabel 4. Hasil uji tarik pipa

\begin{tabular}{ccccc}
\hline \multirow{2}{N}{$\begin{array}{c}\text { N } \\
\mathbf{0}\end{array}$} & $\begin{array}{c}\text { Sifat } \\
\text { Mekanik }\end{array}$ & \multicolumn{2}{c}{ Hasil uji (\%) } & API.5CT. \\
\cline { 3 - 4 } & No3 & No5 & $\begin{array}{c}\text { Gr.80 } \\
\text { Psi } \\
\text { kgf/mm }\end{array}$ \\
\hline 1 & $\begin{array}{l}\text { Kuat tarik } \\
\text { kgf/mm }\end{array}$ & 87,2 & 97,3 & 70,3 \\
\hline \multirow{2}{*}{2} & $\begin{array}{l}\text { Kuat } \\
\text { luluh } \\
\text { kgf/mm }\end{array}$ & 64,8 & 72,4 & $\begin{array}{c}56,7- \\
77,3\end{array}$ \\
\hline 3 & $\begin{array}{l}\text { Elongasi } \\
(\%)\end{array}$ & 19,4 & 13,8 & Min 12 \\
\hline
\end{tabular}

\subsection{Hasil Uji Keras}

Pengujian kekerasan dengan menggunakan metode Vickers menggunakan indentor intan dengan beban $500 \mathrm{~kg}$ pada masing-masing spesimen. Pengujian kekerasan dilakukan dalam 5 kali titik pengujian pada posisi potongan melintang dan hasil pengujian kekerasan ditunjukkan pada Tabel 5 berikut.

Tabel 5. Hasil uji keras Vickers (VHN) pada potongan melintang pipa No 3 dan 5

\begin{tabular}{ccc}
\hline No & Pipa No. 3 & Pipa No. 5 \\
\hline 1 & 231 & 256 \\
\hline 2 & 231 & 256 \\
\hline 3 & 231 & 285 \\
\hline 4 & 231 & 285 \\
\hline 5 & 220 & 270 \\
\hline Rata-rata & 229 & 270 \\
\hline
\end{tabular}

\subsection{Hasil Metalografi}

Pipa ini termasuk pipa tak berkampuh (Seamless pipe) yang ditunjukkan pada Gambar 5.

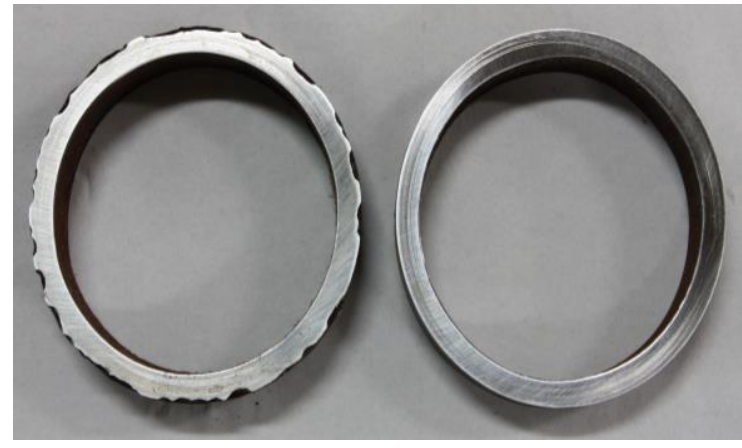

Gambar 5 : Potongan pipa arah melintang No.3 dan No 5 yang memperlihatkan jenis pipa tanpa sambungan (seamless)
Pemeriksaan makro dilakukan pada penampang ujung ulir pipa No 3 yang telah mengalami slek akibat gesekan dan penggetasan oleh lingkungan korosif pada celah antara ulir dalam dan luar. Hal ini material tersebut akan mengalami penipisan yang akhirnya akan mengalami patah (cracking corrossion). Sebagai ilustrasi dapat dilihat pada Gambar 6 .

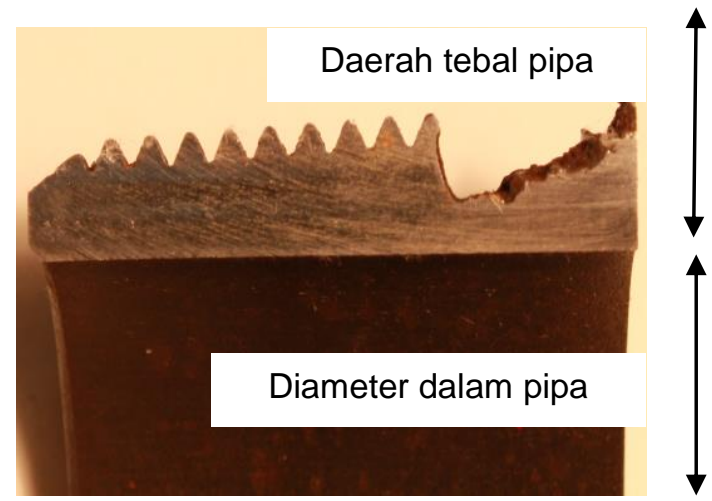

Gambar 6 : Penampang ujung ulir pipa No3 yang telah mengalami slek, (lihat tanda panah)

\subsection{Pemeriksaan Struktur Mikro}

Hasil pemeriksaan struktur mikro pada pipa No3, memperlihatkan struktur yang terbentuk adalah ferit-perlit (ferit berwarna terang, perlit berwarna gelap) dengan kekerasan rata-rata $220 \mathrm{HV}$, dan kondisi struktur masih normal (Gambar 7a). Hasil pemeriksaan struktur mikro pada pipa No5, memperlihatkan struktur ferit-perlit (ferit berwarna terang, perlit berwarna gelap). Struktur perlit pada pipa No 5 lebih dominan di dibanding dengan struktur perlit pada pipa No 3, dengan kekerasan rata-rata pada material pipa No 5 adalah $270 \mathrm{HV}$. Dengan demikian kekerasan material pipa No 5 lebih tinggi dibanding material pipa No 3 (Gambar $7 b)$. 


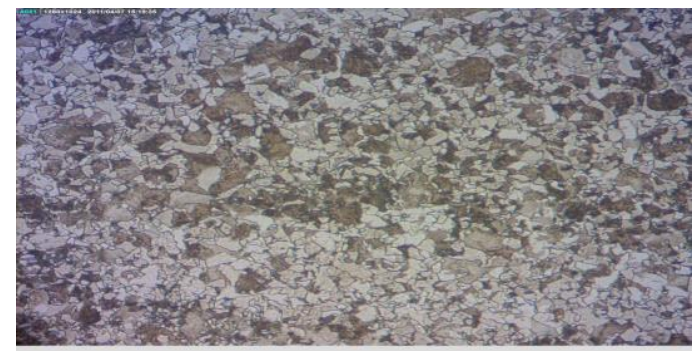

(a)

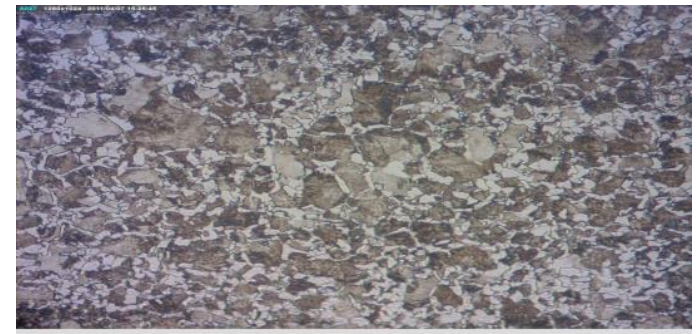

(b)

Gambar 7: Struktur dalam material pipa berupa ferit dan perlit; (a) pipa No 3, (b) pipa No 5. Etsa Nital 2\%, perbesaran 200x

\subsection{SEM dan EDS}

Pemeriksaan SEM memperlihatkan produk korosi dibagian yang cukup tebal dan rapat pada pipa 3 dan No 5 (Gambar 8). Produk korosi tersebut bersifat getas dan memiliki sifat porous, sehingga korosi yang berlapis-lapis akan rentan terhadap lingkungan alkalis. Produk korosi yang yang berlapis-lapis akan rentan terhadap lingkungan korosif seperti ion $\mathrm{CL}^{-1}$ dan ion $\mathrm{SO}^{-2}$ karena bersifat porous sehingga dapat berpenetrasi pada logam dasarnya. Di samping itu terlihat pada foto visual permukaan telah terjadi korosi yang dimungkinkan akibat sejenis mikroba (corrossion microbatic) seperti ditunjukkan pada Gambar 8.

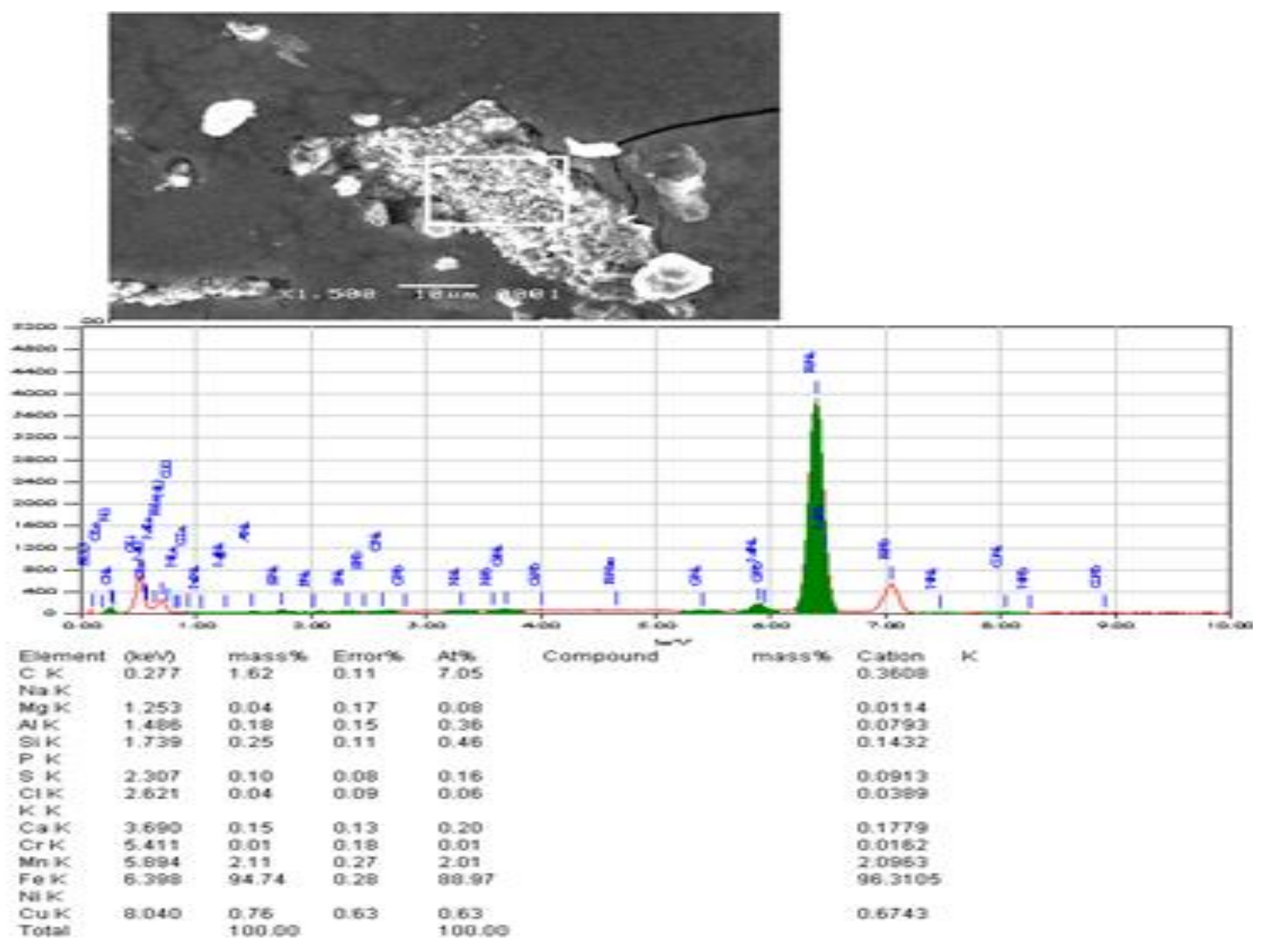

Gambar 8 : Hasil uji SEM-EDS pada permukaan korosi (komposisi senyawa kerak pada daerah patahan). 


\subsection{Pemeriksaan EDS}

Pengujian komposisi senyawa kerak pada daerah patahan dan daerah permukaan slek akibat korosi dan gesekan, dilakukan dengan uji EDS dapat dilihat pada Tabel 6 dibawah ini.

Tabel 6. Hasil uji komposisi kerak dengan EDS pada pipa No 3 dan 5

\begin{tabular}{|c|c|c|c|c|c|c|c|}
\hline \multirow{2}{*}{ No } & \multirow{2}{*}{ Unsur } & \multicolumn{3}{|c|}{ Daerah Patahan } & \multicolumn{3}{|c|}{ Daerah Slek Ujung Ulir } \\
\hline & & I & II & III & I & II & III \\
\hline 1 & Karbon (C) & 5,53 & 1,62 & 4,50 & - & - & - \\
\hline 2 & Natrium (Na) & 0,15 & - & - & - & - & - \\
\hline 3 & $\begin{array}{l}\text { Magnesium } \\
(\mathrm{Mg})\end{array}$ & 0,22 & 0,04 & 0,18 & 0,06 & 0,45 & - \\
\hline 4 & Silika (Si) & 1,07 & 0,25 & 0,83 & 2,77 & 2,80 & 0,18 \\
\hline 5 & Fosfor $(\mathrm{P})$ & - & - & 0,04 & 0,22 & 0,09 & 0,18 \\
\hline 6 & Sulfur (S) & 0,06 & 0,10 & 0,09 & 0,24 & 1,50 & 0,17 \\
\hline 7 & Klor $(\mathrm{Cl})$ & 0,17 & 0,04 & - & 0,01 & 0,65 & 0,42 \\
\hline 8 & Kalium (K) & 0,07 & - & 0,09 & - & 0,34 & 0,22 \\
\hline 9 & Kalsium (Ca) & 0,45 & 0,15 & - & 0,06 & 1,57 & 0,10 \\
\hline 10 & Besi (Fe) & 90,11 & 94,74 & 93,99 & 93,85 & 79,76 & 76,40 \\
\hline 11 & Oksigen $(\mathrm{O})$ & - & - & - & 0.98 & 12,85 & 22,47 \\
\hline
\end{tabular}

Komposisi kimia senyawa kerak bagian permukaan daerah slek pada ujung ulir dan daerah patahan dari contoh pipa umumnya mengandung $\mathrm{Fe}$ dan $\mathrm{O}$ sebagai produk korosi. Produk korosi yang terjadi pada lingkungan Aqueous berwarna merah kecoklatan dan merupakan lapis lindung, akan tetapi memiliki karakteristik porous, sehingga korosi yang terjadi berada dalam lingkungan alkalis dengan reaksi elektrokimia sebagai berikut:

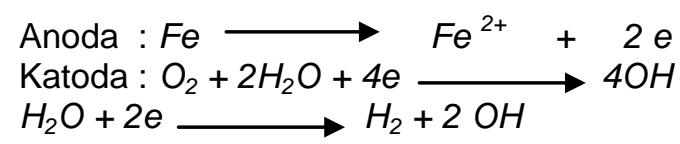

Dengan reaksi totalnya:

$\mathrm{Fe}+2 \mathrm{H}_{2} \mathrm{O} \longrightarrow \mathrm{Fe}(\mathrm{OH})_{2}+\mathrm{H}_{2}$

Adanya $\mathrm{O} 2$ memungkinkan terbentuknya $\mathrm{Fe}$ $(\mathrm{OH})_{2}$, yaitu:

$2 \mathrm{Fe}(\mathrm{OH})_{2}+\mathrm{H}_{2} \mathrm{O}+1 / 2 \mathrm{O}_{2} \longrightarrow 2 \mathrm{Fe}(\mathrm{OH})_{2}$

Dari hasil uji EDAX (Tabel 4) ditemukan adanya khlorida $(\mathrm{CL})$ pada permukaan korosi atau serbuk korosi yang konsentrasinya yaitu $0,17-0,42-0,65 \%$. Ion khlorida dikenal sebagai ion yang sangat agresif dan sangat potensial untuk terjadinya korosi sumuran, sehingga dapat berpenetrasi kedalam lapis lindung $\mathrm{Fe}(\mathrm{OH})_{2}$ atau $\mathrm{FeOH}_{2} \mathrm{O}$ maupun $\mathrm{Fe}$ $(\mathrm{OH})_{3}$ atau $\mathrm{Fe}_{2} \mathrm{O}_{3} 3 \mathrm{H}_{2} \mathrm{O}$. Terjadinya korosi sumuran ditunjukkan pada Gambar 9.
Dengan adanya ion khlorida tersebut maka total reaksi elektronika yang berlangsung adalah :

$\mathrm{Fe}^{2+}+\mathrm{H}_{2} \mathrm{O}+2 \mathrm{CL} \longrightarrow \mathrm{Fe}(\mathrm{OH})_{2}+\mathrm{HCL}$

Propagasi sumuran akan berlangsung secara autocatalytic pada suatu saat bila ada tegangan yang melebihi tegangan maksimum bahan maka retakan tidak dapat dihindari.

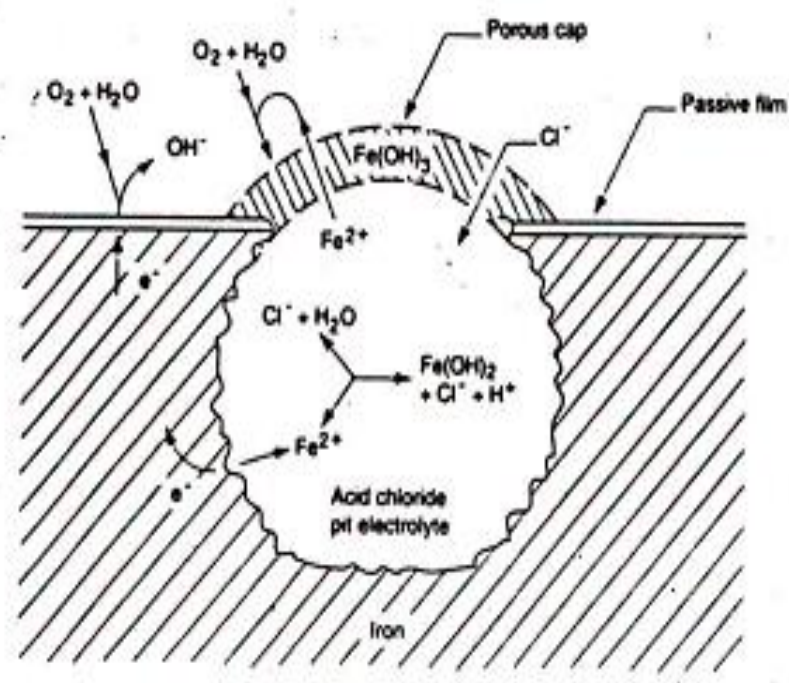

Gambar 9 : Profil korosi sumuran . 


\section{KESIMPULAN}

Dari hasil pengujian, analisa dan pembahasan dapat disimpulkan sebagai berikut:

Secara visualisasi permukaan pipa ulir telah terjadi korosi merata berwarna merah kecoklatan.

Hasil komposisi kimia termasuk baja karbon medium termasuk spec API 5 C5 Gr $\mathrm{N}-80$. Hasil pemeriksaan makro terlihat pada ujung ulir ada penipisan ketebalan yang disebabkan oleh korosi celah (crevice corrossion ), hasil mikrostruktur memiliki struktur ferit-perlit dengan kondisi masih normal ,hasil SEM \& EDS menunjukkan adanya unsur korosif seperti $\mathrm{CL}^{-}$dan $\mathrm{S}^{-2}$ sehingga sangat potensial untuk terjadinya serangan korosi sumuran ,terjadinya slek pada ujung ulir disebabkan oleh lapisan pasivasi $\mathrm{Fe}_{2} \mathrm{O}_{3}$ yang sifatnya mengabsorbsi anion-anion agresif seperti $\mathrm{CL}^{-}$dan $\mathrm{S}^{-}$ 2 ,selanjutnya penulis sarankan yaitu pada daerah ulir kelonggaran disesuaikan dengan ketentuan teknis dan pada korosi permukaan perlu dilakukan analisis mikrobiologi untuk mengetahui adanya mikro organisme tertentu.

\section{DAFTAR PUSTAKA}

1. Timothy Hill, Koch Refining, Pine Bend, MN, Journal "Heater Tube Life Management", National Petroleum Refiners Association Plant Maintenance Conference, May 22$25,2010$.

2. Helmut Thielsch,"Defects and Failures in Pressure Vessels and Piping", Publising by Robert E. Krieger, Malabar, Florida. 7-11. 2009

3. Francis Wildy, "Fire heater optimation", AMETEK process Instruments, Freeport Road - Pittsburgh. 2009
4. R. E. Smallman, CBE, DSc, FRS, FREng, FIM And R. J. Bishop, PhD, CEng, MIM, "Modern Physical Metallurgy and Materials Engineering", Science, process and applications, Sixth Edition, Reed Educational and Professional Publishing Ltd 1995, 168-181.2010

5. W. R. Warke, "Failure Analysis And Prevention”, Stress-Corrosion Cracking, ASM Handbook, Vol.9, 1810. 2011

6. Colangelo and Heiserc, "Analysis of Metalurgical Failures", Jhon Wiley \& Son Inc, New York, p1-2.81-84. 2009

7. Bruce L. Bramfitt, "Carbon And Alloys Steel", Handbook of Materials Selection Edited by Myer Kutz, JOHN Wiley \& Sons inc, New York, p 32 36. 2012

8. "Metallography and Microstructures", ASM Handbook, Vol.9, 2435, 2686,2010

9. William C. Leslie, "The Physical Metallurgy of Steels", Mc-Graw-Hill Company, Bruce L. Bramfitt, "Carbon And Alloys Steel", Handbook of Materials Selection Edited 185, 14-17. 2009

10. ....." Corrosion", Introduction, ASM Handbook, Vol.13, 11, 33. 2011

11. George E. Dieter, "Mechanical Metallurgy", SI Metric Edition, McGraw-Hill, 289. 2012

12. ....."Ferrous Material Specifications", Materials, ASME ॥ Part A, ASME Boiler \& Pressure Vessel Code, New York, 205 - 219. 2009

13. G Antaki, "Piping And Pipeline Engineering”, Design, Construction, Maintenance, Integrity And Repair, Marcel Dekker. 2011 